\title{
DEMANDA DE IRRIGAÇÃO SUPLEMENTAR PARA A CULTURA DO MILHO NO ESTADO DE MINAS GERAIS ${ }^{1}$
}

\author{
Roberto Araújo de Faria ${ }^{2}$, Antônio Alves Soares ${ }^{3}$, Gilberto C. Sediyama ${ }^{4}$ \& \\ Carlos Antônio Álvares Soares Ribeiro ${ }^{5}$
}

\begin{abstract}
RESUMO
Com o emprego de um modelo de balanço hídrico e de técnicas de sistema de informações geográficas, a demanda máxima diária de irrigação suplementar para a cultura do milho, no Estado de Minas Gerais, foi simulada e espacializada. Consideraram-se solos de textura grossa (disponibilidade total de água - DTA: $0,6 \mathrm{~mm} \mathrm{~cm}^{-1}$ ), média $\left(\right.$ DTA $=1,2 \mathrm{~mm} \mathrm{~cm}^{-1}$ ) e fina $\left(\right.$ DTA $\left.=1,8 \mathrm{~mm} \mathrm{~cm}^{-1}\right)$. As precipitações dependentes diárias foram estimadas em nível de $75 \%$ de probabilidade, utilizando-se a distribuição gama, enquanto a evapotranspiração diária foi em nível de $50 \%$ de probabilidade, utilizando-se o modelo proposto por Penman-Monteith (Smith, 1991). Identificou-se, espacialmente, a melhor época de plantio para o milho, considerando-se a menor demanda de irrigação.
\end{abstract}

Palavras-chave: Zea mays L., irrigação suplementar, SIG

\section{DEMAND OF SUPPLEMENTAL IRRIGATION FOR CORN IN THE STATE OF MINAS GERAIS, BRAZIL}

\begin{abstract}
Using a soil water balance model and a geographical information system, the daily maximum demand of supplemental irrigation for corn in the state of Minas Gerais was simulated and spacialized, for coarse (total available water - TAW: $0.6 \mathrm{~mm} \mathrm{~cm}^{-1}$ ), medium (TAW $=1.2 \mathrm{~mm} \mathrm{~cm}^{-1}$ ) and fine (TAW $=1.8 \mathrm{~mm} \mathrm{~cm}^{-1}$ ) soils. The daily dependable precipitations were estimated using the gamma distribution at $75 \%$ of probability and the daily evapotranspiration was computed using the Penman-Monteith (Smith, 1991) with 50\% probability. The best planting date considering the lower supplemental irrigation demand was spacialized.
\end{abstract}

Key words: Zea mays L., supplemental irrigation, GIS

Recebido em 24/09/1999, Protocolo 110/99

${ }^{1}$ Parte da dissertação de Mestrado do primeiro autor, realizado com apoio da Capes

${ }^{2}$ Eng. Agrônomo, M.Sc. Eng. Agrícola, Doutorando em Economia Rural, Departamento de Economia Rural, Universidade Federal de Viçosa, Viçosa, MG, CEP 36571 - 000, Fone: (0xx31) 899 2214. E-mail: raf@alunos.ufv.br

${ }^{3}$ Prof. Ph.D, Departamento de Engenharia Agrícola, DEA/UFV. Fone: (0xx31) 899 2730, Fax: (0xx31) 8992735. E-mail: aasoares@mail.ufv.br

${ }^{4}$ Prof. Ph.D, Departamento de Engenharia Agrícola, DEA/UFV. Fone: (0xx31) 899 2730, Fax: (0xx31) 8992735. E-mail: sediyama@mail.ufv.br

${ }^{5}$ Prof. Ph.D, Departamento de Engenharia Florestal, DEF/UFV. Fone: (0xx31) 899 1210, Fax: (0xx31) 8992478. E-mail: cribeiro@mail.ufv.br 


\section{INTRODUÇÃO}

Dentre os diversos usos dos recursos hídricos, a irrigação destaca-se pela importância socioeconômica em regiões agrícolas áridas e semi-áridas, onde é praticada para suplementar a precipitação natural no atendimento das necessidades hídricas das culturas.

Para otimização do uso de recursos hídricos disponíveis, é de fundamental importância, na elaboração de um projeto de sistema de irrigação racional, o conhecimento da demanda de água das culturas, do processo de retenção de água nos solos, da contribuição das chuvas e das perdas operacionais.

Vários autores (Doorenbos \& Pruitt, 1977; Silva, 1982; Bernardo, 1995) recomendam dimensionar o projeto de irrigação por meio do balanço entre a evapotranspiração e a precipitação, com certo nível de probabilidade.

Segundo Costa (1991) apesar de o modelo de balanço hídrico possuir variáveis aleatórias em sua composição, a simulação pode ser feita de maneira determinística, substituindo-se o valor aleatório por um valor fixo, com certa probabilidade de ocorrência.

Estudos de verificação da probabilidade de atendimento da demanda hídrica das culturas a partir de métodos climatológicos, têm sido realizados para várias localidades brasileiras, principalmente utilizando-se a análise de distribuição das chuvas e o método do balanço hídrico (Oliveira, 1990).

De acordo com Almeida (1995) a distribuição gama de dois parâmetros tem sido empregada no ajustamento de freqüências de totais de precipitação, observados sob diferentes condições de clima, em intervalos diários, semanais, quinzenais e mensais. Sob as mais variadas condições climáticas, essa distribuição tem-se mostrado adequada para descrever a distribuição das quantidades de chuva.

Geralmente, o projetista, ao elaborar seus projetos de irrigação, utiliza informações climatológicas de estações meteorológicas situadas em locais muitas vezes distantes da área a ser irrigada, o que acaba acarretando erros na estimativa da demanda de irrigação, em escala regional.

Com o objetivo de quantificar a variação espacial na demanda hídrica das culturas, Hashmi et al. (1995) modelaram espacialmente, empregando técnicas de interpolação disponíveis em um Sistema de Informações Geográficas (SIG) com mapas climáticos pontuais e de uso do solo, a variabilidade dos parâmetros usados para estimar a evapotranspiração regional da bacia do "Cache la Poudre", no Colorado, Estados Unidos. Concluíram que a versatilidade do sistema, ao se considerar as variabilidades espacial e temporal dos parâmetros usados no cálculo da evapotranspiração proporciona, aos pesquisadores, poderosa ferramenta para análise espacial e, ainda, que a técnica permite abranger, com muita agilidade e precisão, grandes regiões; além disso, possibilita analisar, de maneira mais confiável, as interações entre os parâmetros de interesse.

O presente trabalho teve por objetivo espacializar, no Estado de Minas Gerais, a demanda máxima diária de irrigação suplementar real necessária à cultura do milho e identificar, espacialmente, a melhor época de plantio para esta cultura.

\section{MATERIAL E MÉTODOS}

Os dados climatológicos foram cedidos pelo INMET (Instituto Nacional de Meteorologia) e pela ANEEL (Agência Nacional de Energia Elétrica); nesta, as estações meteorológicas apresentavam somente dados de pluviometria. O período adotado foi de 1961 a 1978 e as estações selecionadas foram aquelas que apresentavam série histórica mínima de 10 anos para precipitação e de cinco anos para evapotranspiração.

Das 85 estações operadas pelo INMET a que os autores do presente trabalho tiveram acesso, apenas 35 apresentavam séries históricas com período mínimo de 10 anos (disponibilizando pluviometria e parâmetros para estimativa da evapotranspiração) além de 16 estações, cuja série histórica variava de 5 a 10 anos; portanto, para a estimativa da evapotranspiração em todo o Estado de Minas, contou-se com 51 estações.

As estações da ANEEL não apresentavam dados necessários à estimativa da evapotranspiração, parâmetro essencial ao modelo descrito, apresentando apenas pluviometria, razão por que, para as 62 estações pluviométricas selecionadas, adotaram-se os parâmetros para estimativa da evapotranspiração (temperatura máxima, temperatura mínima, temperatura do bulbo úmido, velocidade do vento e insolação) segundo o critério de localização em relação às 51 estações do INMET.

Nas regiões montanhosas, como o Sul de Minas e a Zona da Mata, a distância entre as estações meteorológicas do INMET e da ANEEL não poderia ultrapassar 20 quilômetros, a fim de se aproveitar, como dados locais, os valores de evapotranspiração da estação do INMET vizinha, mas em outras regiões mais planas, como o Norte de Minas, essa distância foi ampliada em até 100 quilômetros.

Para simulação do balanço de água no solo a partir de dados climáticos, desenvolveu-se um software através do programa Delphi versão 1.0.

No cálculo do balanço de água no solo foi utilizada a metodologia apresentada em Souza (1993) desenvolvida em termos de déficit de água no solo, tendo como referência a umidade à capacidade de campo.

Estimou-se a precipitação dependente empregando-se uma rotina computacional para transformar a série histórica diária de dados pluviométricos em uma série qüinqüidial, cujos valores encontrados foram ordenados de maneira crescente e, posteriormente, empregou-se a distribuição gama de probabilidade (descrita em Assis et al. 1996) para estimar a precipitação dependente, a nível de $75 \%$ de probabilidade, isto é, quantidade mínima de precipitação com $75 \%$ de probabilidade de ocorrência.

As alturas médias qüinqüidial de precipitação, por dia chuvoso, usadas na distribuição gama, foram calculadas para cada sequiência de cinco dias e localidade, empregando a metodologia descrita por Sediyama et al. (1996).

A evapotranspiração de referência (ETo) foi estimada usando-se o modelo proposto por Penman-Monteith conforme Smith (1991) e a evapotranspiração da cultura foi calculada, em cada período, empregando-se o coeficiente da cultura proposto por Doorenbos $\&$ Pruitt (1977) e o coeficiente de umidade do solo proposto por Bernardo (1995). Estimou-se o número de dias de cada estádio do milho conforme a faixa de variação da temperatura do ar, segundo metodologia proposta por Coelho (1978). 
Para cada data de plantio, o modelo implementado analisou os diferentes turnos de rega ao longo do ciclo e elegeu-se o menor turno de rega como parâmetro fixo para nova simulação de irrigação na data de plantio correspondente. Para cada ciclo simulado, o programa elege a lâmina máxima de irrigação suplementar real necessária aplicada no turno de rega fixo e, dividindo-se seu valor pelo turno de rega, tem-se a demanda máxima diária de irrigação suplementar real necessária.

As simulações foram feitas para datas de plantio diariamente, ao longo de todo o ano, estimando-se as demandas máximas diárias de irrigação suplementar real necessária para cada ciclo da cultura. Dentre as demandas máximas de cada data de plantio ao longo do ano foi selecionado o valor máximo de cada estação meteorológica e, a seguir, realizada a espacialização dessa variável, no Estado de Minas Gerais, mediante o emprego de técnicas do Sistema de Informações Geográficas (SIG). Repetiu-se o procedimento considerando-se três tipos de solo: de textura grossa $(\mathrm{G})$, média $(\mathrm{M})$ e fina $(\mathrm{F})$, respectivamente com disponibilidades totais de água (DTA) de $0,6,1,2$ e 1,8 $\mathrm{mm} \mathrm{cm}^{-1}$.

Para espacialização do pico anual da evapotranspiração de referência utilizou-se o software de informação geográfica IDRISI 1.0 para Windows, desenvolvido pelo Departamento de Geografia da Clark University nos EUA e disponível no Departamento de Engenharia Agrícola da Universidade Federal de Viçosa. O interpolador do IDRISI trabalha com um raio de busca variável, que pode utilizar os seis pontos amostrados mais próximo do ponto interpolado ou utilizar todos os pontos de controle (Eastman,1992). Nesse estudo optou-se por utilizar os seis pontos mais próximo e o expoente da função distância igual a quatro o qual, em teste preliminares, produziu melhores resultados para o caso em questão.

\section{RESULTADOS E DISCUSSÃO}

As percentagens de área do Estado de Minas são apresentadas na Tabela 1, por classe de demanda de irrigação suplementar real necessária e acumulada, para solos de textura grossa, média e fina. Ressalta-se que o valor proposto não leva em conta as perdas por deriva e evaporação, que devem ser consideradas na aplicação da lâmina bruta de irrigação.

Observa-se, na Tabela 1, que há tendência para maior demanda máxima de irrigação suplementar quando o solo é de textura grossa, relativamente àqueles de textura média e fina. As

Tabela 1. Áreas ocupadas, em \%, das diferentes classes de demanda máxima de irrigação suplementar real necessária aos solos de textura grossa, média e fina, no Estado de Minas Gerais

\begin{tabular}{|c|c|c|c|c|c|c|}
\hline \multirow{3}{*}{$\begin{array}{c}\text { Demanda } \\
\text { Máxima } \\
\left(\mathrm{mm} \mathrm{dia}^{-1}\right)\end{array}$} & \multirow{2}{*}{\multicolumn{2}{|c|}{$\frac{\text { Grossa }(\mathrm{G})}{\text { Área por }}$}} & \multirow{2}{*}{\multicolumn{2}{|c|}{$\frac{\text { Média (M) }}{\text { Área por }}$}} & \multicolumn{2}{|c|}{ Fina $(F)$} \\
\hline & & & & & & por \\
\hline & Classe & Acum. & Classe & Acum. & Classe & Acum. \\
\hline $4.0-4.5$ & & & 0.04 & 0.04 & 037 & $0 ?$ \\
\hline & 0,4 & 0,40 & 0,64 & 0,68 & 3,31 & 3,68 \\
\hline & 7,20 & 7,60 & 7,94 & 8,62 & 22,66 & 26,34 \\
\hline & 9,79 & 17,39 & 29,03 & 37,65 & 21,11 & 47,45 \\
\hline & 28,37 & 45,76 & 18,47 & 56,12 & 17,84 & 65,29 \\
\hline $6,5-7$ & 18,69 & 64,45 & 30,09 & 86,21 & 24,23 & 89,52 \\
\hline $7,0-7,5$ & 26,00 & 90,45 & 12,43 & 98,64 & 9,26 & 98,78 \\
\hline $7,5-8,0$ & 7,83 & 98,28 & 0,49 & 99,13 & 1,22 & 100,00 \\
\hline $8,0-8,5$ & 1,20 & 99,48 & 0,40 & 99,53 & 0,00 & 0,00 \\
\hline $8,5-9,0$ & 0,52 & 100,00 & 0,47 & 100,00 & 0,00 & 0,00 \\
\hline
\end{tabular}

menores demandas de irrigação estão entre 4,0 a 5,0 mm dia-1, independentemente do tipo de solo. Abaixo da classe de 6,0 a $6,5 \mathrm{~mm} \mathrm{dia}^{-1}$, tem-se uma porcentagem de áreas atendidas de $45,8,56,1$ e $65,3 \%$ em solos de textura grossa, média e fina, respectivamente, distribuídas de forma ampla, em todo o Estado (Figura 1). Para demanda acima de 7,0 $\mathrm{mm} \mathrm{dia}^{-1}$, com a irrigação suplementar real necessária tem-se apenas $9,5 \%$ da área em textura $\mathrm{G}, 1,4 \%$ em textura $\mathrm{M}$ e $1,2 \%$ em textura $\mathrm{F}$.

As classes acumuladas em \% para as três classes de solos apresentadas na Tabela 1 foram agrupadas e plotadas no gráfico correspondente à Figura 1.

Constata-se, na Tabela 1, que áreas com valores de demanda acima de 7,5 $\mathrm{mm} \mathrm{dia}^{-1}$ aparecem somente no solo de textura grossa, devido ao fato deste solo apresentar menor DTA, resultando na necessidade de irrigações mais freqüentes. Destarte, os métodos de irrigação que utilizam alta frequiência na aplicação da água (turno de rega pequeno) como pivô central e irrigação localizada, são mais adequados para irrigar o solo de textura grossa, enquanto o de textura média apresenta comportamento mais próximo ao do solo de textura fina para valores de demanda acima de 7,5 $\mathrm{mm} \mathrm{dia}^{-1}$ e comportamento análogo ao do solo de textura grossa, para valores de demanda abaixo de 5,5 $\mathrm{mm} \mathrm{dia}^{-1}$. Metade da área do Estado de Minas Gerais possui demanda de irrigação suplementar abaixo de $6,0 \mathrm{~mm} \mathrm{dia}^{-1}$ para solo de textura fina e abaixo de $6,5 \mathrm{~mm} \mathrm{dia}^{-1}$, para solos de textura média e grossa.

As demandas máximas (considerando-se o plantio ao longo de todo o ano) de irrigação suplementar real necessária à cultura do milho, são apresentadas na Figura 1 (A, B e C), respectivamente, para solos de textura grossa $(\mathrm{A})$, média $(\mathrm{B})$ e fina $(\mathrm{C})$.

Verificou-se que as demandas de irrigação suplementar real necessária entre 6,0 e 7,5 $\mathrm{mm} \mathrm{dia}^{-1}$ ocupam $73,1 \%$ da área do Estado. Quando a simulação do balanço hídrico é feita em solos de textura $\mathrm{G}$, as demandas entre 5,5 e 7,0 $\mathrm{mm} \mathrm{dia}^{-1}$ ocupam 77,6\% da área em solos de textura $\mathrm{Me}$ e, entre 5,0 e 7,0 $\mathrm{mm} \mathrm{dia}^{-1}$, ocupam $85,9 \%$ da área em solos de textura F. Observa-se, então, distribuição espacial mais uniforme das classes em Minas, quando a simulação é feita em solo de textura fina, ou seja, é importante conhecer a localização do projeto ao se trabalhar com solos que possuam altos valores de disponibilidade total de água; além disso, independente do tipo de solo, pode-se caracterizar quatro regiões nas quais predominam valores de demanda de irrigação suplementar real necessária, acima de 7,0 $\mathrm{mm}$ dia $^{-1}$; estão elas localizadas nas áreas do Médio Jequitinhonha, Noroeste de Minas, extremo Norte de Minas e parte do Triângulo Mineiro. Vale ressaltar que os resultados apresentados são para o plantio em qualquer época do ano, uma vez que os valores tomados referem-se à situação mais crítica do ano, considerando-se a contribuição natural das chuvas.

A época de plantio ao longo do ano em que a cultura do milho apresentou menor consumo de irrigação suplementar real necessária durante todo o seu ciclo, foi espacializada e está apresentada na Figura 2. Como não se observou grande diferença com relação ao tipo de solo, utilizaram-se os valores da simulação do solo de textura média, já que este apresentou resultados intermediários.

A Tabela 2, apresenta as áreas com as melhores épocas de plantio do milho em condições de sequeiro, no Estado de Minas Gerais. 


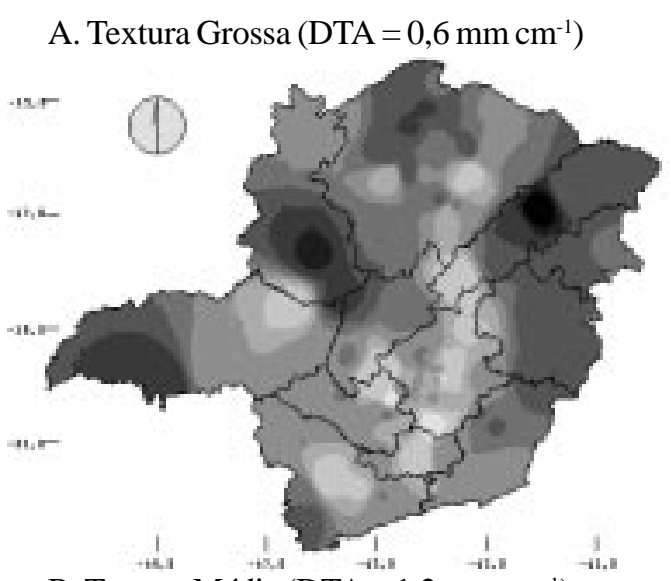

B. Textura Média (DTA $=1,2 \mathrm{~mm} \mathrm{~cm}^{-1}$ )

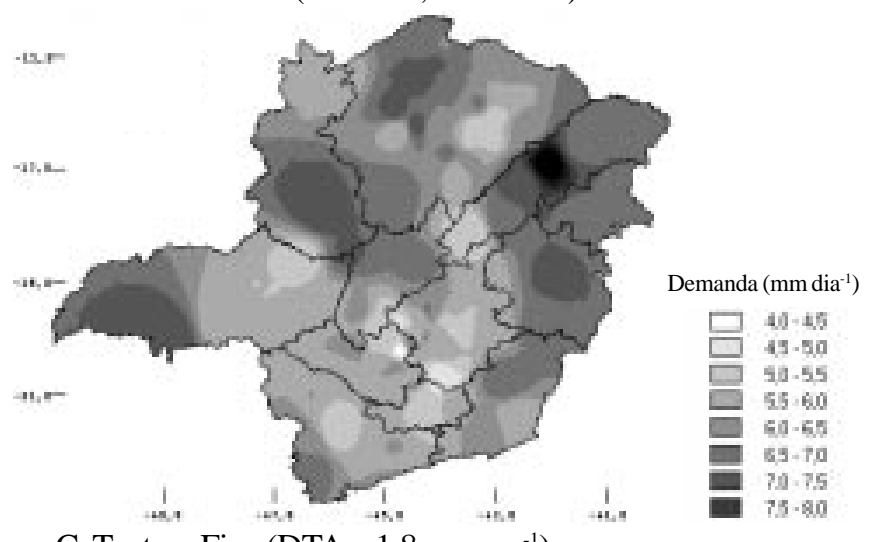

C. Textura Fina $\left(\mathrm{DTA}=1,8 \mathrm{~mm} \mathrm{~cm}^{-1}\right)$

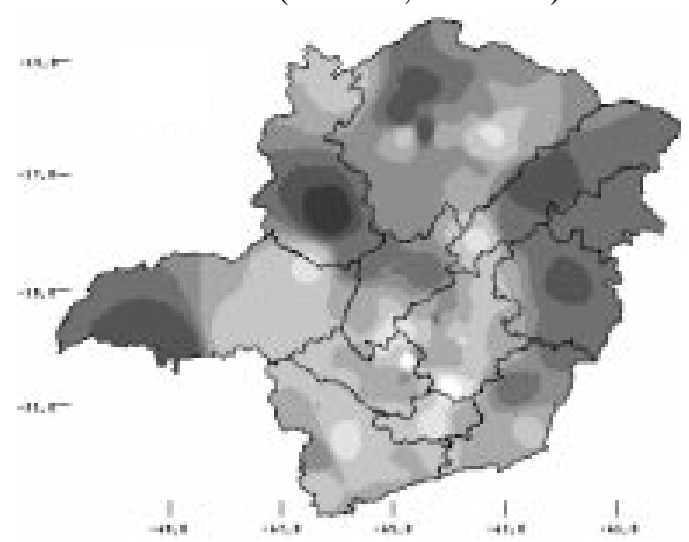

Figura 1. Demanda máxima de irrigação suplementar real necessária ao milho, em solos de texturas diferentes

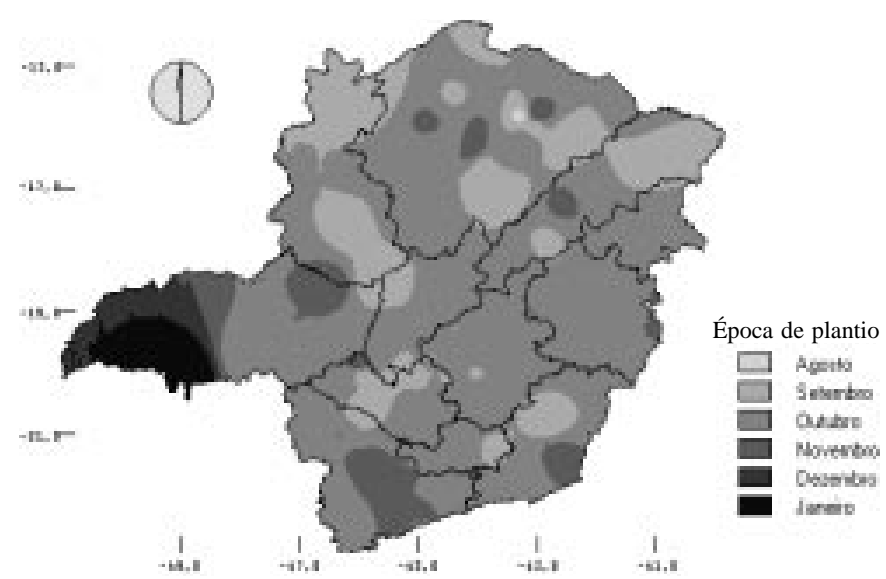

Figura 2. Melhor época para plantio do milho em condições de sequeiro, no Estado de Minas Gerais
Tabela 2. Áreas ocupadas pelas melhores épocas de plantio do milho em condições de sequeiro, no Estado de Minas Gerais

\begin{tabular}{lcccccc} 
Mês & Ago & Set & Out & Nov & Dez & Jan \\
Área $(\%)$ & 0,07 & 20,48 & 65,15 & 8,28 & 2,85 & 3,17 \\
\hline
\end{tabular}

Observa-se, na Figura 2 e na Tabela 2, predominância dos meses de setembro e outubro $(85,63 \%$ da área) como sendo os meses de plantio que otimizaram a necessidade de irrigação suplementar real necessária, considerando-se todo o ciclo da cultura; logicamente, esta é a época em que o plantio de milho deve ser realizado sob condições de sequeiro, pois o aproveitamento da precipitação natural seria otimizado; naturalmente, tal indicação preliminar deverá ser confrontada com as condições da época de colheita, de preços de mercado, de secagem etc., sob pena de frustração da safra. Os meses de agosto, dezembro e janeiro, como resultados da simulação, não devem ser considerados, pelo fato de que esses meses resultam da extrapolação de uma área com densidade baixa de estações meteorológicas e por ser agosto um dado isolado.

Finalmente, constatou-se uma não homogeneidade espacial relativa ao comportamento da demanda de irrigação suplementar real necessária no Estado em estudo. O trabalho ressalta, assim, a necessidade de se levar em consideração a variação espacial das necessidades hídricas das culturas a serem implantadas e os sistemas de irrigação a serem instalados, a disponibilidade da fonte de água e os tipos de solo, na elaboração de políticas que visem ao desenvolvimento sustentado das bacias hidrográficas que compõem o Estado de Minas Gerais.

\section{CONCLUSÕES}

1. A demanda de irrigação suplementar real necessária varia de acordo com a região, realçando a importância de o projetista estar atento à localização do sistema de irrigação ao adotar, no seu projeto, o critério de irrigação suplementar.

2. Com a irrigação suplementar, as classes de demanda para a cultura do milho acima de $7,5 \mathrm{~mm} \mathrm{dia}{ }^{-1}$ os solos de textura grossa, média e fina ocupam respectivamente apenas 9,55, 1,36 e 1,22\% da área do Estado de Minas Gerais.

3. Independente do tipo de solo, pode-se caracterizar quatro regiões onde predominam valores de demanda de irrigação suplementar real necessária à cultura do milho, acima de 7,0 $\mathrm{mm} \mathrm{dia}^{-1}$, localizadas nas áreas do Médio Jequitinhonha, noroeste de Minas, extremo norte de Minas e parte do Triângulo Mineiro.

4. A melhor época de plantio do milho de sequeiro são os meses de setembro a outubro, predominando em $85,6 \%$ no Estado de Minas Gerais.

5. O gerenciamento dos recursos hídricos do Estado de Minas Gerais deve ser regionalmente discutido, uma vez que se constatou uma não homogeneidade espacial relativa à demanda de irrigação suplementar, independente do tipo de solo utilizado na simulação.

\section{REFERÊNCIAS BIBLIOGRÁFICAS}

ALMEIDA, R.M.B. Características climatológicas do regime de chuva em Minas Gerais. Viçosa,MG: UFV, 1995. 64p. Dissertação Mestrado 
ASSIS, F.N.; ARRUDA, H.V.; PEREIRA, A.R. Aplicações de estatística à climatologia: Teoria e prática. Pelotas: UFPel, 1996.161p.

BERNARDO, S. Manual de irrigação. 6. ed. Viçosa, MG: UFV, $1995.657 \mathrm{p}$.

COELHO, D.T. The consideration of temperature in corn (Zea mays L.) growth and development models. West Lafayette: Purdue University, 1978. 70 p. Ph.D. Thesis

COSTA, M.H. Modelo de otimização dos recursos hídricos para irrigação, conforme a época de plantio. Viçosa,MG:UFV, 1991. 111p. Dissertação Mestrado

DOORENBOS, J.; PRUITT, W.O. Guidelines for predicting crop water requirements. Rome: FAO, 1977. 144p. Irrigation and Drainage Paper, 24

EASTMAN, J.R. IDRISI technical reference. Massachusetts: Clark University, 1992.213p.

HASHMI, M.A.; GARCIA, L.A.; FONTANE, D.G. Spatial estimation of regional crop evapotranspiration. Transaction of the ASAE ,St. Joseph, v.38, n.5, p.1345-1351, 1995.
OLIVEIRA, D. Evapotranspiração máxima e necessidade de água para irrigação de feijão (Phaseolus vulgaris L.) e trigo (Triticum aestivum $\mathrm{L}$.) determinadas por balanço hídrico para seis locais do Paraná. Piracicaba : ESALQ, 1990. 155p. Dissertação Mestrado

SEDIYAMA, G.C.; MELO, J.S.P.; ALVES, A.R. Determinação dos parâmetros da distribuição gama, em função das alturas médias mensais de precipitação dos dias chuvosos. Revista Ceres, Viçosa, MG, v. 43, n. 247, p. 254-266, 1996.

SILVA, C.L. Estimativa do uso consumitivo de água e da irrigação suplementar, para algumas culturas no Vale do Rio São Francisco. Viçosa, MG: UFV, 1982. 46p. Dissertação Mestrado SMITH, M. Report on the expert consultation on revision of FAO methodologies for crop water requirements. Rome: FAO, 1991.45p.

SOUZA, E.F. Modelo computacional aplicado ao manejo e planejamento de irrigação. Viçosa, MG: UFV,1993. 65p. Dissertação Mestrado 